\title{
MEMORIA QUEBRADA Y CONSENSO MEDIÁTICO DE LA TRANSIGIÓN
}

\author{
Rosa María Ganga Ganga \\ Universidad de Alicante
}

Se puede entender que la memoria histórica es el recuerdo que tiene una comunidad de su pasado, con todas sus implicaciones respecto a los valores que transmite, las conductas o habitus que propicia o las propias pautas de producción, reelaboración o caducidad que posee.

Aunque el concepto de memoria viene de la psicología y es personal, se ha ido ampliando con el tiempo. Actualmente, cuando se habla de memoria histórica o colectiva se hace referencia a una construcción más o menos consensuada a partir de las memorias personales y de las que han propiciado los distintos poderes e instituciones de la sociedad, incluyendo a los medios de comunicación, desde la prensa escrita a todas y cada una de las industrias culturales tecnológicas, ya que la memoria histórica debe ser transmitida para que realmente pase del ámbito personal al colectivo.

Con frecuencia, la propia memoria histórica de una persona o de un grupo social concreto chocan o no acaba de encajar en esa construcción social que se ha realizado y ambas coexisten a un mismo tiempo. También es cierto que, para minimizar este efecto, las mismas sociedades se encargan de cohesionar, en lo posible, las memorias particulares o grupales para amoldarlas a la memoria histórica hegemónica existente o la que se pretende construir.

Los medios de comunicación y de información juegan un importante papel en estos casos, de tal forma que la prensa escrita y, en especial para lo que interesa en este caso, los productos de los medios audiovisuales, principalmente los del (todavía) medio hegemónico de comunicación, la televisión, suelen cumplir su función de fijación de una determinada memoria colectiva e incluso de su construcción o reconstrucción.

Marc Ferro, indiscutible especialista en las relaciones de cine con la historia, se pregunta sobre esta función del cine y la televisión, salvando, claro está la distancia entre la ficción y la no-ficción:

En la actualidad, con el cine y la televisión, la historia conoce una nueva forma de expresión: ¿aportan algo estos medios a su inteligibilidad? El ejemplo de El acorazado Potemkin está relacionado con este problema: ¿qué imágenes de la revolución de 1905 están más grabadas en nuestra mente sino las escenas del film de Eisenstein? Sin embargo, al igual que sucede con la batalla de bolas de nieve del Napoleón de Abel Gance, estas escenas proceden directamente de la imaginación de los autores. 
El impacto ideológico de estas obras maestras, de las premisas históricas que planteaban, ha sido tan fuerte que durante mucho tiempo un santo respeto ha impedido proceder a su análisis, juzgado como un sacrilegio por todos aquellos para los que el cinematógrafo era como un nuevo Evangelio (Ferro, 2000:191).

Esta función de los medios audiovisuales, en concreto del cine y la televisión (por ser el medio de transmisión mayoritario de la producción documental) es la que está en la base del presente trabajo, que intentará poner en relación algunos aspectos de la memoria colectiva de un periodo de la historia de España relativamente cercano, aunque no tanto como para que no se haya formado, y hasta deformado, una memoria histórica sobre él: la transición política de la dictadura a la democracia, con la construcción que algunos documentales hacen de dicha etapa histórica y de su memoria.

Paloma Aguilar, que ha investigado sobre la memoria y la desmemoria de la Guerra Civil durante la transición y sobre los efectos que tuvo en el desarrollo de la misma, habla de la memoria colectiva en su obra Memoria y olvido de la Guerra Civil española. La define como un elemento importante del proceso de cambio en la transición:

Dicho elemento es la memoria colectiva que consta del recuerdo que tiene una comunidad de su propia historia, así como de las lecciones y aprendizajes que, más o menos conscientemente, extrae de la misma. Esta variable incluye tanto el contenido de la memoria (recuerdo de los acontecimientos históricos específicos) como los valores asociados a su evocación (lecciones y aprendizajes históricos), modificados, frecuentemente, por las vicisitudes históricas del presente (Aguilar, 1996:25).

Tanto el recuerdo de los acontecimientos históricos como los valores asociados están en disposición de ser re-construidos o alterados, al menos en cierta medida, por los medios audiovisuales, como vehículos hegemónicos de las informaciones que recibe, hoy en día, gran parte de la sociedad. Por eso, los documentales que tratan sobre el periodo de la transición política realizan un relato histórico marcado por un determinado modelo historiográfico y una ideología concreta, muy lejos de la supuesta objetividad del macrogénero y muy cerca, por contra, de la servidumbre a determinados intereses.

La producción cinematográfica de documentales durante la transición fue bastante interesante, pues supuso una especie de revulsivo al anquilosado NODO y su producción oficialista durante toda la dictadura:

Durante los años de la Transición democrática el género documental experimenta un auge en España. Paralelo a una monolítica producción NO-DO, que irá evidenciando un anacronismo cada vez mayor hasta su desaparición en mayo de 1981, el panorama cinematográfico de tipo documental ofrece productos variados e interesantes, de diversos formatos y, en algunas ocasiones, de gran valentía estética y discursiva.

La necesidad de reinterpretar un pasado que había sido hiper-ideologizado durante los casi cuarenta años que duró la Dictadura parece encontrar su mejor modo de expresión en el campo de la no ficción, al suponerse éste lugar de contacto con materiales pertenecientes a la realidad (Gómez Vaquero, 2005:21). 
Algunos de estos documentales, aún teniendo siempre en cuenta que toda película documenta su propio referente, tienen una clara vocación de dar testimonio de su época, de construir la realidad social y la historia del presente, como La vieja memoria, de Jaime Camino (1977); Informe General, de Pere Potabella (1977); Numax presenta..., de Joaquín Jordá (1979); Después de... de Cecilia y José Juan Bartolomé (1981), entre otros.

Cabe destacar la película de los hermanos Bartolomé Después de... (1981), dividida en dos partes: No se os puede dejar solos y Atado y bien atado, rodadas entre 1979 y 1980, en plena efervescencia política pero ya en lo que se ha llamado «el desencanto», que sus directores prefieren llamar «el descontento». Esta película del cine «independiente» español, realizada con pocos medios materiales y un reducido equipo humano fue depositada para su autorización en la Dirección General de Cinematografía poco antes del golpe de Estado del 23-F. Estuvo secuestrada por la administración durante meses, privada de todas las subvenciones a las que tenía derecho e incluso se denunció a los autores por supuesto delito, con la excusa de que, en cierto modo, pronosticaban el citado golpe antes de suceder.
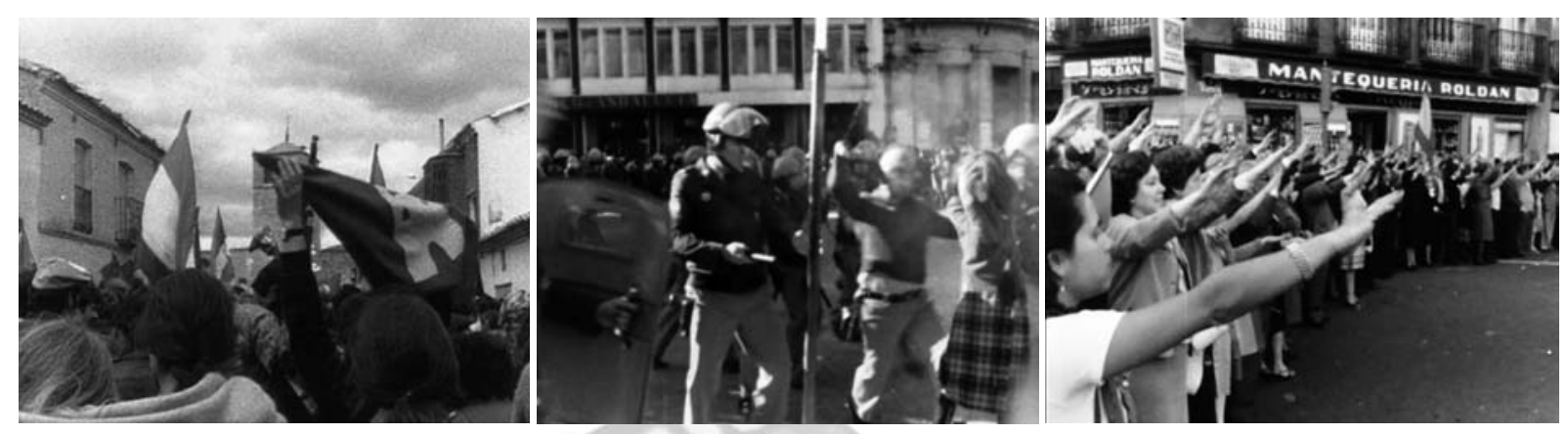

Tres imágenes de la película Después de...: Manifestación en Villalar de los Comuneros, represión policial en Sevilla y concentración fascista en Madrid.

Puesto que la película ofrece un mosaico dialéctico de intervenciones de todo tipo de gentes, grabadas en los lugares en los que se sucedían reivindicaciones, protestas, mítines y actos varios de la izquierda, la extrema izquierda, la ultraderecha y de personas no necesariamente organizadas en partidos, con pocos comentarios omniscientes y muchos testimonios de gente descontenta con la parte de transición que se había hecho y con la que se estaba haciendo todavía, está claro que la construcción de la realidad social e histórica (de la historia del presente) que dicha película realizó no gustó en las esferas del poder ni en los grandes y no tan grandes partidos, entre otras cosas porque no se ajusta a lo que se ha dado en llamar «tesis canónica de la transición», ni, por lo tanto, a la memoria que se quiere transmitir a través de las instituciones mediáticas. En todo caso se trata de una construcción de la memoria poco usual y minoritaria en los medios, sea cine o televisión. También las películas de Portabella y Jordá se pueden considerar en esta línea y presentan, además, un lenguaje audiovisual innovador que pone el énfasis en su propia forma de producción o en su propia materialidad.

En contraste, la producción cinematográfica de documentales sobre la transición a posteriori, ya entrados los ochenta, y en los noventa y comienzos del siglo XXI es bastante exigua, puesto que la inmensa mayoría de documentales sobre la transición o sobre algún aspecto concreto de ésta son programas para la televisión. Además, por las características del negocio 
televisivo generalista posterior al monopolio estatal, necesitado de audiencias abultadas y emisiones para amplios sectores de público, hacen un tratamiento bastante diferente de los materiales y los testimonios con los que construyen la narración y la argumentación audiovisual y parten de unos presupuestos históricos e ideológicos y de unos modos de producción diferentes.

La producción televisiva se compone de documentales únicos o seriados, realizados por alguna de las grandes cadenas nacionales de televisión o de alguna de las comunidades autónomas o por productoras independientes, por encargo de cualquiera de las anteriores. En realidad, se puede decir que hasta mediados de los noventa, cuando se estrena la serie La Transición, no se realiza ningún documental importante, por lo que la mayor parte de los años ochenta del siglo XX no hubo apenas emisiones documentales sobre la transición, aunque, casi a finales de los ochenta, se comenzó a producir y realizar la serie citada.

El paradigma de este tipo de documentales sobre la transición y, además, el primero que se realizó, es, como se ha dicho, la serie de TVE La Transición. Esta serie, que se estrenó en pleno verano de 1995 por la segunda cadena (La 2, ahora), tuvo un periodo de producción bastante extenso. En la temporada de 1986/87 Elías Andrés, realizador de TVE, y Victoria Prego, redactora, presentaron a la empresa el proyecto para la realización de una serie documental sobre la transición, que fue aprobado. En 1993, según el realizador y la subdirectora, tuvieron que dar por acabada la serie por imposición de la dirección, tras el montaje de trece capítulos, que tardaron otros dos años en emitirse, entre julio y octubre de 1995.

Una producción así sólo podía abordarla una empresa pública como TVE. Los problemas que tuvo la serie al final de su montaje y postproducción son debidos, fundamentalmente (aunque no en exclusiva), a la exorbitante cantidad de tiempo empleado en la producción. Ninguna otra de las jóvenes cadenas de televisión, ni las autonómicas ni las privadas hubiesen podido costear ni mantener un equipo tanto tiempo en la producción de un solo programa, sin contar con su falta de archivo histórico propio, lo que hubiese encarecido todavía más la serie.

En todos los documentales de divulgación histórica subyace un determinado supuesto histórico-historiográfico, que tiende a ajustarse a la forma de entender la historia que es dominante en los medios de comunicación y la que propicia, en mayor medida que otras, una determinada construcción de la memoria histórica. La serie La Transición se atiene a una concepción histórica e historiográfica evenemencial y positivista. Este modelo tiende a explicar la historia como una serie de acontecimientos puntuales y como una sucesión de acciones concretas de unos personajes individualistas y heroicos que son, en toda ocasión, miembros de las altas esferas del poder (reyes, gobernantes, generales) y de las élites de las sociedades que historian, y propugna una historia abocada al progreso continuo. Ese, precisamente, es también el modelo de la tesis canónica sobre la transición, que resume Javier Tusell de la siguiente forma:

Se produjo un cambio con unos costes sociales no muy altos y permitiendo que el régimen democrático, a pesar de un punto de partida nada positivo, se consolidara rápidamente. Sin producirse una ruptura, como pretendía la oposición, tuvo lugar algo muy parecido a ella, pero por procedimientos reformistas. La transición fue completa, sin detenerse en la incertidumbre del camino a seguir (como en la Rusia de Gorbachev) y sin dejar que perduraran "enclaves autoritarios", como en el caso de Chile con Pinochet. Tampoco se autoperpetuó la clase política adaptándose de forma ficticia al nuevo panorama institucional, como en algunos países balcánicos, sino que se convirtió de forma sincera a los principios democráticos (Tusell, 1999:26). 
Existen otras versiones de la transición, aunque minoritarias, como la que defienden Carme Molinero y Pere Ysàs, en su libro Trabajadores disciplinados y minorías subversivas. Clase obrera y conflictividad laboral en la España franquista, que ven la transición como una etapa más compleja, admiten cierto liderazgo de los reformistas pero también hacen hincapié en el papel determinante de los agentes sociales. En todo caso no es éste el modelo predominante ni en los medios de comunicación ni entre los historiadores, mayoritariamente adscritos a la tesis canónica sobre la transición.

Y este es el modelo historiográfico de La Transición, que la serie no sólo acata sino que desarrolla con profusión y con exclusión de cualquier otra hipótesis posible. De este modo se puede decir que ha servido para colaborar activamente en la configuración de un tipo de memoria histórica positivista en varias generaciones de españoles, a pesar de chocar con la memoria personal de muchos de ellos, desde los medios de comunicación audiovisuales, sobre todo desde la televisión (también se ha editado en VHS y en DVD), pero también desde los primeros niveles docentes (primaria y secundaria), puesto que se ha utilizado para «explicar» la transición política a los jóvenes alumnos, sin aportar otros discursos divergentes o hacer un análisis crítico (se podría hablar, pues, de una doble función de este documental).

\section{LA SERIE}

El modelo histórico antes descrito tiene sus correlatos narrativos en la serie, a través de las estrategias que utiliza en la construcción del texto audiovisual. En primer lugar, se privilegian los acontecimientos políticos puntuales, especialmente aquellos que se desean resaltar y que son los que aparecen en la trama principal (la lucha del Héroe y sus ayudantes por sacar adelante, contra viento y marea, los cambios que lleven a la democracia), por medio de una jerarquización basada fundamentalmente en la duración del tiempo del relato, de forma que el tiempo histórico representado no es, ni mucho menos, uniforme en relación al primero. Asimismo, se recurre a la tematización de las acciones y los acontecimientos, de forma tal que, junto con el tratamiento desigual del tiempo representado y la propia selección de los acontecimientos incluidos en la trama, promueve una suerte de encuadramiento de estos.

En segundo lugar, los personajes protagonistas, el Rey y Suárez, son los héroes indiscutibles, casi míticos (sobre todo el Rey), que deben luchar denodadamente contra todo y pertenecen a las elites políticas originadas por el franquismo y a las altas esferas del poder (en esto igual que los antagonistas principales). También los ayudantes de los protagonistas y antagonistas y los testigos entrevistados para la serie pertenecen a esta categoría citada. Y habría que resaltar la ausencia de expertos historiadores o de otras disciplinas, que suelen funcionar como argumentos de autoridad en los clásicos documentales históricos.

En cambio, en tercer lugar, apenas existen los personajes colectivos, ni siquiera la sociedad, los movimientos obreros o sociales que se movilizaron intensamente durante la transición tienen una función activa importante. Por lo tanto, tampoco sus acciones o su contribución, son tenidas en cuenta.

En cuarto lugar, al pertenecer al género documental, la narración y la argumentación van de la mano y se confunden con frecuencia, de tal manera que la narración de cómo se 
hicieron los primeros cambios de la transición queda acoplada en muchos momentos con la argumentación que hace la voz en off o la de los testigos entrevistados.

Por último, el tratamiento del tiempo es fundamentalmente lineal, con algunos flashbacks y con algunos capítulos montados con secuencias alternadas, sin perder por ello la condición de linealidad general, tendente siempre a ir en un progreso continuo en el proceso de transición.

Como muestra de la forma en que se produce esta representación de la historia, se va a realizar un breve análisis del primer capítulo de la serie.

Los hechos narrados en el capítulo primero de La Transición se sitúan entre los días 20 de diciembre del año 1973 al 4 de enero del 74, es decir, entre el asesinato de Carrero Blanco, secuencia con la que se abre la serie, y la toma de posesión de Arias Navarro. Además de estas dos, se da cuenta de las reacciones que provocó el atentado en diversos ámbitos, del Proceso 1001, cuyo juicio estaba fijado para ese mismo día, de la rueda de prensa de ETA, así como de las maniobras del entorno de Franco para que fuese nombrado presidente Carlos Arias.

A todo esto acompañan una serie de secuencias menores, que presentan un montaje de programas navideños, de fin de año (incluido el discurso de Franco) y anuncios publicitarios, cuya finalidad es servir como signos de puntuación y raccords, para disminuir la tensión dramática y de somera contextualización audiovisual. Y, para acabar, un Happy End nostálgico con el Yesterday cantado por Massiel sobre un montaje que muestra a Franco como un ancianito entrañable y la salida del último Seiscientos de la SEAT, con los felices obreros de la fábrica despidiéndolo.

La construcción de la historia y de la realidad social del momento se realiza a partir de la selección y tematización del material de archivo disponible (ya sea del archivo de TVE, de NODO o comprado a los de otras televisiones europeas) o grabado ex profeso. Es evidente que esa selección se ha hecho con un criterio de espectacularización, por el cual el capítulo tiende a conceder más importancia a las imágenes o sonidos que llamen la atención, especialmente en la secuencia del atentado, del que, sin embargo no hay imágenes directas reales, por lo que se ha optado por "tomar prestadas" las de una película de ficción: Operación Ogro (Gillo Pontecorbo, 1979), eso sí, debidamente pasadas por el generador de efectos para reducir sus colores al monocromo blanco y negro, y que así casen con las de archivo.
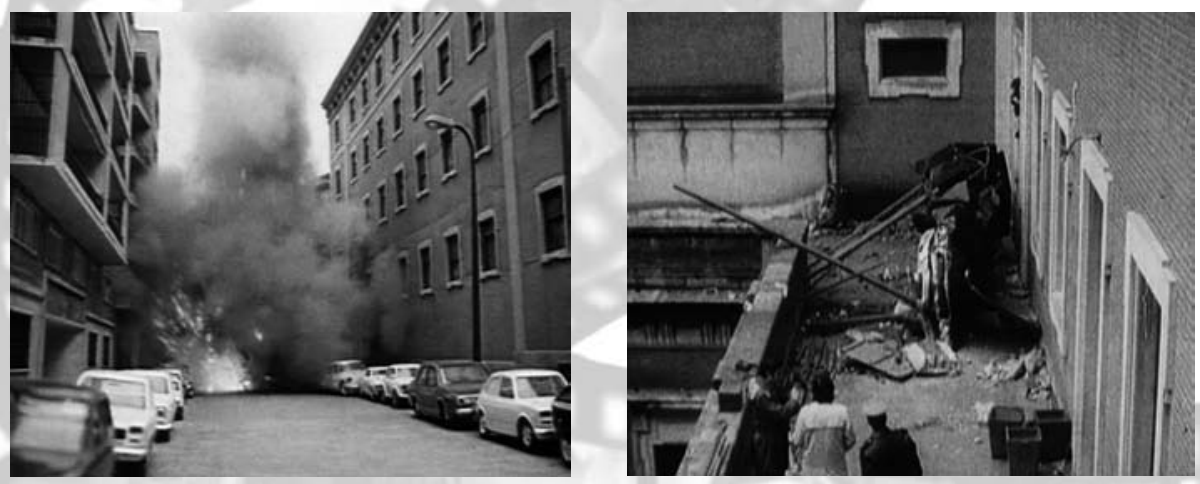

A la izquierda, imagen de la película Operación Ogro. A la derecha, imagen documental de los restos del coche de Carrero Blanco. 
Prácticamente todas las secuencias presentan acontecimientos puntuales y políticos que hacen referencia al mundo político del régimen de Franco o a sus apéndices. Por otra parte, se puede constatar que hay elementos del contexto social, cultural y económico e incluso político que se han dejado de lado, así como prácticamente cualquier referencia a la vida cotidiana de los españoles. Existe, pues, una clara exclusión de acontecimientos molestos o no considerados utilizables por la enunciación, aparte de la minimización de otros, y de personas o personajes, en este caso, principalmente, la gente común y la oposición de base.

Los personajes de la serie son tanto físicos como colectivos. El hecho de empezar el capítulo con el entierro tiene una significación muy especial, puesto que la serie trata precisamente sobre el entierro simbólico del régimen franquista para dar paso a la democracia. No es casualidad la elección de los personajes que echan las paladas de tierra sobre el muerto: la Iglesia, la Monarquía, el Ejército y el Gobierno, encarnados en el Cardenal Tarancón, el Príncipe Juan Carlos, un militar (hijo del fallecido) y el presidente en funciones Fernández Miranda. A casi todos ellos se les asigna, a partir de aquí, un papel y una función activas, de héroe y ayudantes (aunque el Ejército sólo en parte), en definitiva, de hacedores del cambio. Luego aparecerán otros muchos (como actores o como testigos entrevistados), especialmente Suárez, que en esos momentos «solo» era director general de TVE, pero es aquí donde empieza a quedar marcado el papel de los principales actantes, y donde se comienza a ver cuáles serán los personajes olvidados.

De entre todos los personajes, el entonces Príncipe y luego Rey Juan Carlos es, sin ninguna duda, quien mejor dibujado queda a lo largo de toda la serie (aunque su papel en el primer capítulo no sea, todavía, importante), pues no sólo se le asigna la función de héroe indiscutible sino que se intenta, además, presentarlo como un español corriente, cercano a la gente, o tal vez, como sustituto virtual de esa gente que tiene tan poca presencia en la serie. Esta configuración de la figura del Rey se da no sólo en lo verbal, que es considerable, sino también, quizá de forma más sutil pero igualmente efectiva, en lo icónico, como cuando se muestra al Príncipe en situaciones familiares, jugando con los niños o proyectando a su familia películas de súper-8, o mostrarlo (y describirlo) solo y altivo tras el féretro de Carrero Blanco. En ambos casos se trata una forma de dar al personaje cualidades humanas positivas.
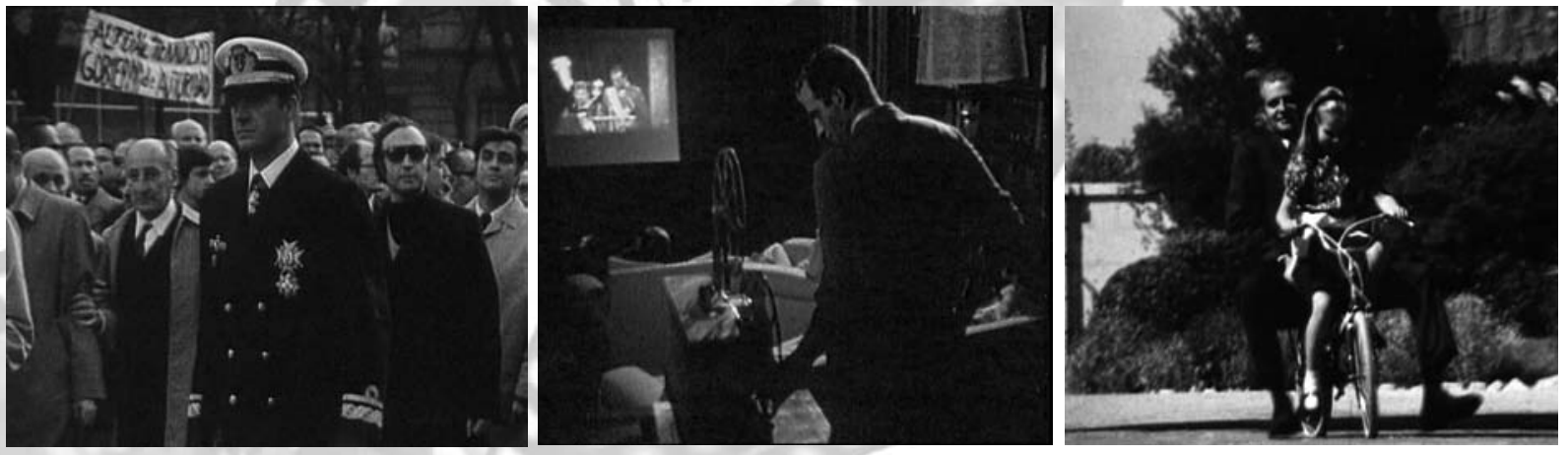

El Príncipe en el entierro de Carrero Blanco y en dos escenas familiares

Por otra parte, los espacios que muestra y que describe este capítulo de la serie son institucionales, urbanos e incluso mediáticos. La ciudad (Madrid, sobre todo) es el lugar donde ocurren las cosas en esa España que se nos presenta y representa. Pero una ciudad que no es la de las casas particulares ni las calles por las que caminan la gente sino la oficial, la institu- 
cional, pues la calle está presente prácticamente sólo como escenario de lo que se considera un importante acontecimiento político: el atentado contra el presidente del Gobierno.

En el relato histórico audiovisual nos encontramos con el tiempo del transcurrir histórico, por una parte y el tiempo más breve del relato, por otra. Hay, pues, que recurrir a las elipsis y seleccionar los momentos o los procesos más interesantes del flujo continuo del tiempo real para adaptarlo al de la narración, pero resulta interesante comprobar que cuanto más extenso es un relato en relación con el tiempo histórico, más importancia jerárquica se le está concediendo. Así, hay momentos o acontecimientos a los que se dedica muy poco tiempo y otros que se pretenden alargar todo lo posible, como ocurre en este capítulo.

En el relato La Transición el tiempo está tratado de forma preferentemente lineal y cronológica, aunque este capítulo presenta un flashback poco extenso pero muy significativo: contextualiza la figura de Carrero Blanco en relación con su nombramiento como presidente del Gobierno y sus lealtades, a Franco y al Príncipe. Además, las secuencias del atentado, el juicio del Proceso 1001 y las reacciones, ofrecidas en un montaje alternado, son también un flashback respecto a la primera secuencia del entierro, que no altera, en lo fundamental la linealidad narrativa.

La estructura narrativa que presenta el primer capítulo de la serie La Transición es clásica: se presenta una situación dada (el Régimen estable) a la que un acontecimiento extraordinario hace tambalearse (el atentado); el nudo lo componen las tensiones y maniobras para el nuevo nombramiento y el desenlace es la toma de posesión del recién nombrado, que lleva a un falso Happy End con un Franco ancianito, la despedida del Seiscientos y una canción nostálgica: Yesterday. Las tramas del relato se presentan alternadas en los primero minutos y después, salvo pequeñas excepciones, en riguroso orden cronológico prácticamente diario.

En cuanto a la estructura argumentativa se puede decir que al principio es causal, el atentado es la causa de los efectos desestabilizadores en el interior del régimen y, en menor medida, para el proceso de la transición. Pero después de las primeras secuencias entrelazadas la argumentación es claramente cronológica, con conexiones en las que hace referencia al día en que se encuentra el relato (descripción temporal verbal) y también con conexiones o, más bien, signos de puntuación visuales: hay un fundido a negro al final de cada una de las tres primeras jornadas (descripción temporal visual).

En la mayoría de ocasiones la argumentación, que se centra sobre todo en las consecuencias del atentado y en comenzar a construir al héroe y a los demás personajes, viene por la palabra, a veces por la de las entrevistas, pero casi siempre por la voz en off, que se configura como verdadera conductora de la argumentación, en detrimento de la imagen y de los sonidos originales, verdaderos documentos audiovisuales, a los que tan sólo se deja hablar en la secuencia del atentado.

Además de lo visto hasta ahora, es necesario recordar que la serie La Transición ha supuesto un verdadero vivero, no sólo para TVE, sino también para el resto de los medios de comunicación social españoles, audiovisuales o no. De hecho, el diario El País comenzó a distribuir la serie (con el título de La Transición Española), junto con el periódico, prácticamente al mismo tiempo que la emisión televisiva; el semanario El Tiempo la editó en DVD hace varios años; y a partir de sus imágenes y sonidos se han realizado muchos documentales únicos y series documentales sobre aspectos concretos, personajes o temas de la transición, tanto en la televisión estatal pública como en las privadas nacionales o en varias autonómicas públicas, la mayoría con secuencias icónicas tomadas al completo, sin ni siquiera hacer un 
nuevo montaje visual, aunque, eso sí, con un off adaptado a cada caso, no demasiado lejos, curiosamente, de las argumentaciones y puntos de vista que propone La Transición. Esa es, además del propio texto audiovisual, la importancia de este documental seriado, pues a través de esta apabullantes intertextualidad se refuerzan todas y cada una de las características de la serie.

Se pueden extraer algunas conclusiones del modo en que la serie construye su particular representación de la transición y, de paso, de la memoria histórica, en la parte que le toca. En primer lugar, es una construcción hecha desde el postulado ideológico del consenso que unió a las élites del franquismo y la oposición, es decir, se atiene a la tesis canónica de la transición.

En segundo lugar, se hace desde un ámbito oficial, público y estatal, TVE, en la que los intereses de sus directivos se ajustan a los de quienes dirigen el país en esa etapa (el PSOE) y que fueron, también, protagonistas de la transición (tal vez su poco relevante papel en la serie fuera otra de las causas de los postreros problemas del documental) y de sus pactos, con lo cual existe una comunidad de intereses políticos, económicos y mediáticos en contar la transición como lo hace la serie, desde el modelo oficial y con una visión centralista apenas modificada por los casos de Cataluña y País Vasco, sin que exista nada más en la periferia de Madrid.

En tercer lugar, esta construcción se hace desde la selección, jerarquización, tematización o exclusión de los acontecimientos y los procesos de evolución históricos, de los personajes y de la forma en que configura los espacios y el tiempo o de cómo los olvida, en beneficio de otros más adecuados a la representación simbólica que se desea construir.

Por último, los efectos que la serie persigue conseguir en el espectador, cuyo prototipo es ese espectador modelo que va configurando el propio texto, son: hacerle ver o recordar que la transición fue modélica, sin conflictos y sin sangre, como le gusta repetir a la voz en off; que el Rey fue el principal impulsor de la democracia; que quienes hicieron la reforma fueron dirigentes del Régimen y, por lo tanto, se le debe a éste un respeto, más allá de lo que hubiese hecho (represión, muertes, etc.) anteriormente; que la «oposición democrática» era débil y acató los cambios; que todo se hizo por consenso; que Franco murió en la cama; que la sociedad no tuvo nada que decir ni hacer en el proceso. En fin, se trata de conformar una sociedad desmemoriada de su propia memoria y dócil con los dictados del poder, sea éste el que sea.

\section{BIBLIOGRAFÍA}

FERRO, Marc (2000), Historia contemporánea y cine, Barcelona, Ariel.

GÓMEZ VAQUERO, Laura (2005), «Hibridaciones e imposturas en el documental de la Transición» en María Luisa Ortega (ed.), Nada es lo que parece. Falsos documentales, hibridaciones y mestizajes del documental en España, Madrid, Ocho y medio, pp. 21-46.

MOLINERO, Carmen e YSÀS, Pere (1998), Trabajadores disciplinados y minorías subversivas. Clase obrera y conflictividad laboral en la España franquista, Madrid, Siglo XXI.

TUSELL, Javier (1999), Historia de España en el siglo XX. IV. La transición democrática y el gobierno socialista, Madrid, Taurus. 